\title{
Perancangan Sistem Informasi Peminjaman Buku Perpustakaan Berbasis Web Pada Smp Negeri 3 Huragi
}

\author{
Erniwati Duha', Cindy Juliani² \\ Sistem Informasi, Universitas Islam Negeri Sumatera Utara
}

\begin{tabular}{l}
\hline \hline Article Info \\
\hline Article history: \\
Received Jun $12^{\text {th }}, 2020$ \\
Revised Aug $20^{\text {th }}, 2020$ \\
Accepted Aug $26^{\text {th }}, 2020$
\end{tabular}

\section{Keyword:}

Sistem Informasi, sublime text, PHP MYSQL.

\begin{abstract}
Penelitian ini bertujuan untuk merancang sistem informasi berbasis web pada peminjaman buku perpustakaan di SMP Negeri 3 HURAGI dan untuk mengimplementasikan sistem informasi perpustakaan yang telah dirancang. system informasi sangat diperlukan di perpustakaan agar dapat membantu dalam melakukan tugas administrasi perpus guna meningkatkan mutu pelayanan perpustakaan yang melayani masyarakat untuk lebih giat lagi membaca. Data-data dikumpulkan dengan menggunakan teknik observasi, dan dokumentasi. Sedangkan software yang digunakan adalah PHP sebagai bahasa pemrograman, MySQL sebagai pengelola database. Hasil penelitian akan ditunjukkan bahwa telah dirancang dan diuji cobakan sistem informasi perpustakaan berbasis web pada SMP Negeri 9 Bandung yang dapat menghasilkan informasi mengenai sirkulasi pengelolaan manajemen perpustakaan yang berbasis komputerisasi secara efektif dan efisien.
\end{abstract}

Copyright $\odot 2020$ STMIK Triguna Dharma. All rights reserved.

\author{
First Author \\ Nama : Erniwati Duha \\ Program Studi : Sistem Informasi \\ UINSU \\ Email: erniwduha@gmail.com
}

\section{PENDAHULUAN}

\section{A. Latar Belakang}

Pengetahuan tidak hanya diperoleh dengan pengalaman secara nyata namun juga didapat dari informasi yang diterima. Informasi dapat dilakukan dengan berbagai media, salah satunya dengan membaca buku yang disediakan di perpustakaan. Hal ini sesuai dengan fungsi perpustakaan yaitu sebagai tempat penyimpanan, mengolah, menyajikan, menyebarluaskan,dan melestarikan pengatahuan.

Perpustakaan merupakan bagian dari sumber belajar yang harus dimiliki oleh setiap sekolah atau perguruan tinggi. Karena peserta didik dengan mudah mencari informasi atau ilmu pengetahuan melalui perpustakaan. Perpustakaan adalah suatu kesatuan unit kerja yang terdiri dari beberapa bagian yaitu, bagian pengembangan koleksi, begian pengolahan koleksi, bagian pelayanan pengguna,dan bagian pemeliharaan sarana dan prasarana.

Saat ini Perpustakaan Sekolah Menengah Pertama 9 Bandung khususnya dalam transaksi peminjaman buku masih menggunakan sistem yang konvensional, sehingga rentan terjadi kesalahan dalam hal sirkulasi peminjaman buku yang disebabkan oleh data-data yang belum terdokumentasi dengan baik. Waktu siswa/siswi berkunjung ke perpustakaan juga sangat minim yaitu 15 menit saat jam istirahat.

Hal ini seharusnya dapat diatasi dengan sistem informasi perpustakaan berbasis website, karena dengan sistem informasi berbasis website pengelolaan data perpustakaan dapat lebih efektif sehingga sirkulasi peminjaman buku dapat terdokumentasi dengan baik dan lebih efektif dalam pengoptimalan waktu.
B. Rumusan Masalah Permasalahan yang akan di bahas meliputi :
1. Bagaimana merancang sistem informasi perpustakaan yang berbasis web
2. Bagaimana mengimplementasikan sistem informasi perpustakaan berbasis web.
C. Tujuan Penelitian
Tujuan penelitian meliputi :


1. Untuk merancang bagaimana sistem informasi yang berbasis web pada perpustakaan

2. Untuk mengimplementasikan sistem informasi berbasis web pada perpustakaan.

\section{Manfaat Penelitian}

Adapun manfaatnya:

1. Dengan adanya sistem web ini akan lebih efektif bagi siswa/siswi yang akan meminjam buku.

2. Mempermudah akses ke semua siswa yang ada di sekeliling sekolah.

3. Dan dengan menggunakan sistem komputerisasi ini perpustakaan dapat mengelola transaksi dengan mudah.

\section{TINJAUAN PUSTAKA}

\section{A. Konsep Dasar Sistem}

1. Pengertian sistem

terbagi menjadi dua yaitu pendekatan yang menekankan pada prosedur dan pendekatan yang menekankan pada elemen/komponen.

Pengertian sistem yang lebih menekankan pada prosedur : "suatu sistem adalah suatu jaringan kerja dari prosedur- prosedur yang saling berhubungan, berkumpul bersamasama untuk melakukan suatu kegiatan atau menyelesaikan suatu sasaran tertentu." Pengertian sistem yang menekankan pada prosedur "Sistem adalah setiap kesatuan secara konseptual atau fisik yang terdiri dari bagianbagian dalam keadaan saling tergantung satu sama lainnya".

2. Elemen Sistem

Ada beberapa elemen yang membentuk sistem :

a. Tujuan

Setiap sistem pasti memiliki tujuan, tujuan ini lah untuk memotivasi dan mengarahkan sistem. Tanpa tujuan sistem tidak akan berjalan.

b. Masukan

Masukan (input) adalah sesuatu yang bisa di proses oleh sistem mau itu berupa hal yang berwujud atau tidak berwujud.

c. Keluaran

Keluaran (output) adalah sesuatu hasil dari pemprosesan yang bisa berupa suatu informasi, saran, cetakan laporan dan sebagainya.

d. Proses

Suatu bagian yang merupakan perubahan dari masukan menjadi keluaran yang berguna.

e. Umpan Balik (feedback)

Umpan balik ini dilakukan untuk mengendalikan baik masukan atau pun keluaran.

3. Karakteristik Sistem

Sistem pastinya mempunyai karakteristik yang diantara nya adalah :

a. Komponen sistem

Sistem memiliki beberapa komponen yang saling berinteraksi yang artinya saling bekerja sama untuk mencapai satu tujuan.

b. Batas Sistem

Daerah yang membatasi antara sistem yang satu dengan yang lain atau dengan lingkungan luar

c. Environment

Apapun diluar batas dari sistem yang mempengaruhi dari operasi sistem.

d. Penghubung

Antara sistem yang satu dengan sistem yang lain.

\section{B. Konsep Dasar Informasi}

1. Pengertian Informasi

Informasi adalah data yang dikelola menjadi bentuk yang lebih berguna dan lebih di butuh kan bagi penerima. Informasi memiliki beberapa karakteristik antar nya :

a. Relevant informasi yang di sampaikan harus bersifat relevant dengan apa yang dibutuhkan. 
b. Reliable informasi yang dihasilkan harus terbebas dari kesalahan penyimpangan dan secara tepat menggambarkan kejadian-kejadian atau aktivitas-aktivitas yang terjadi.

c. Complete informasi harus complete dan tidak menghilangkan data data yang dibutuhkan si penerima.

d. Timely informasi harus lah tepat waktu apabila dibutuhkan oleh si penerima.

e. Understandable penyajian informasi haruslah jelas sehingga mudah dimengerti.

f. Verifiable informasi yang dihasilkan harus lah sama dengan hasil yang diperoleh.

\section{PEMBAHASAN}

1. Analisis Kebutuhan Sistem

Perancangan sistem menggukanakan software Xampp, mozila firefox, sublime text, menggunakan bahasa pemograman php.

2. Design Sistem

Gambaran besar design sistem dalam penelitian ini dapat di lihat pada Usecase Diagram. Usecase Diagram adalah mendeskripsikan sebuah interaksi antara satu atau lebih actor dengan sistem informasi yang dibuat. Secara kasar, Use case digunakan untuk mengetahuai fungsi apa saja yang ada didalam sebuah sistem informasi dan siapa saja yang berhak menggunakan fungsi itu.

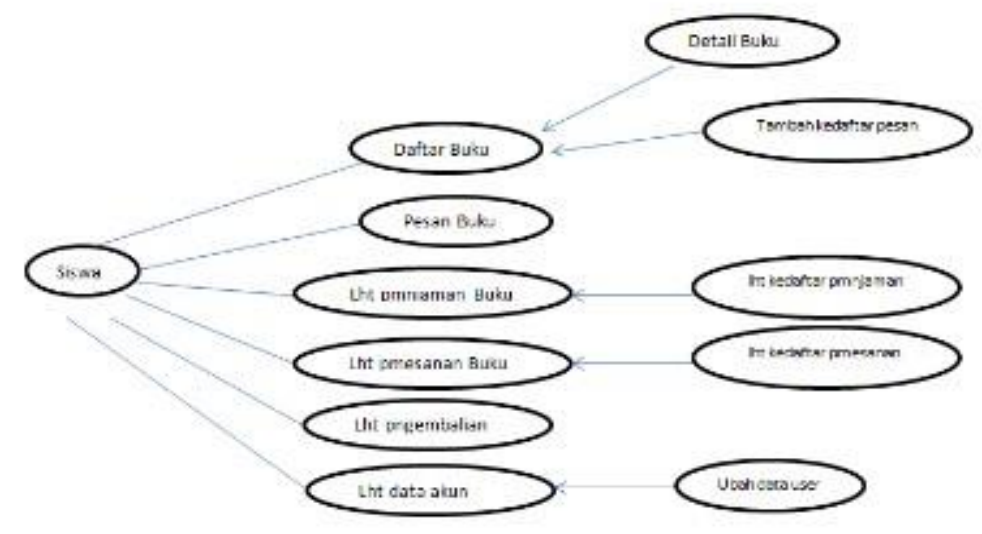

Usecase Diagram Siswa (user)

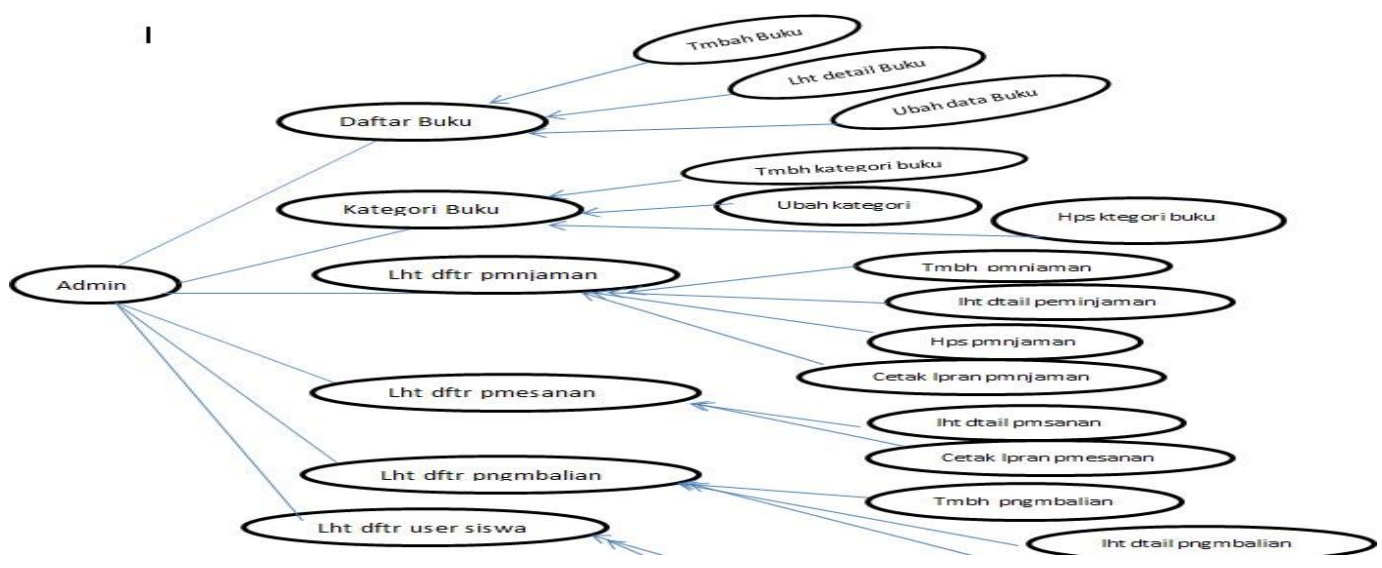




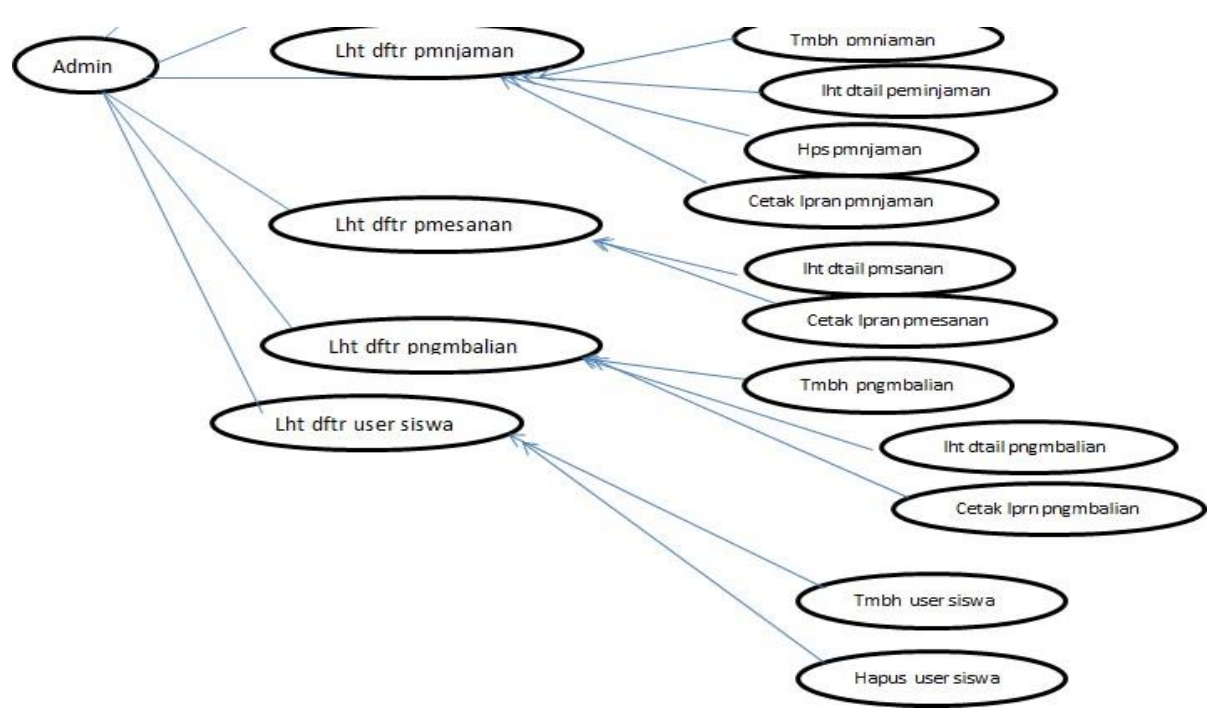

Usecase Diagram Administrator

\section{Implementasi}

Suatu tahap penerspan program yang dibuat berdasarkan hasil analisa dan design yang terperinci pada suatu sistem yang sedang berjalan. Pada aplikasi program ini terdapat dua menu, menu user dan administrator. Sebelum masuk kemenu administrator maupun user terlebih dahulu melakukan login.

a. Tampilan Awal Program

\section{Perpustakan} SMPN 3 HURAGI

Sistem Perpustakaan Online

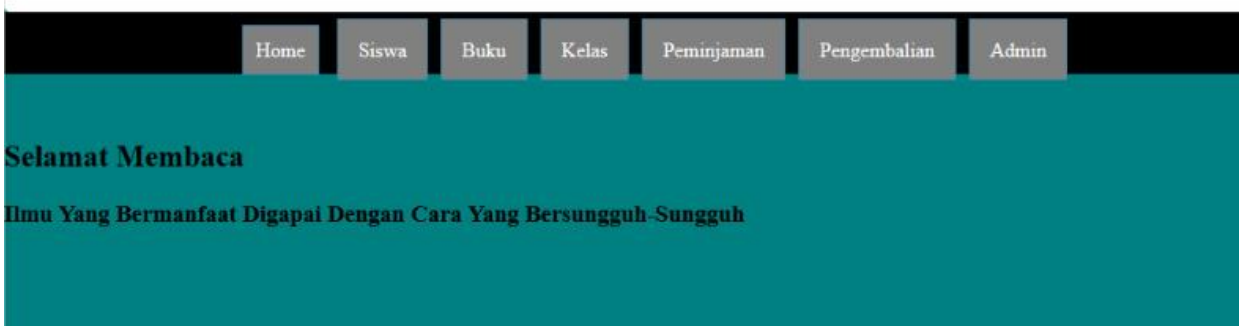

b. Tampilan Data Siswa

\section{Perpustakan}

Sistem Perpustakaan Online

\section{SMPN 3 HURAGI}

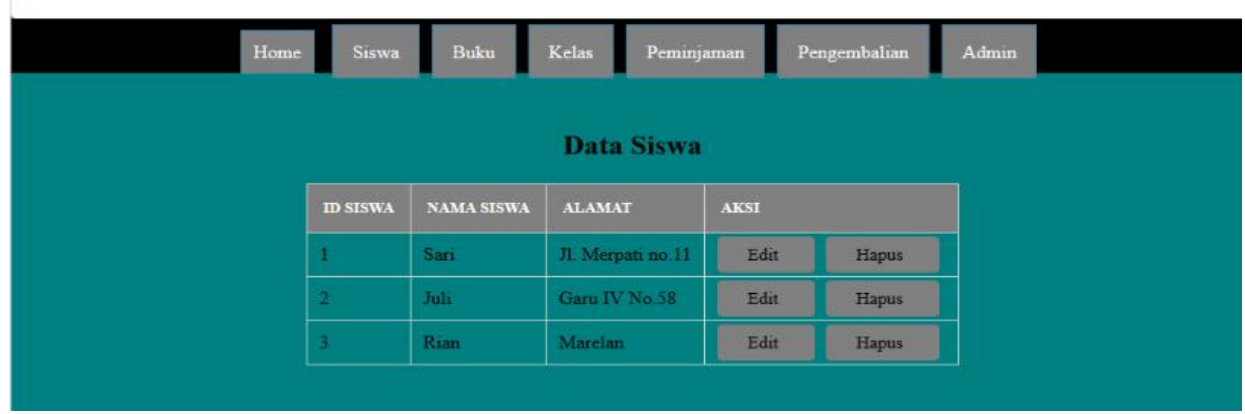

c. Tampilan Data Buku 


\section{Perpustakan}

Sistem Perpustakaan Online

\section{SMPN 3 HURAGI}

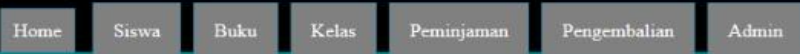

Data Buku

\begin{tabular}{|l|l|l|l|l|l|}
\hline KODE BUKU & JUDUL BUKU & PENGARANG & ID SISWA & AKSI & \\
\hline 1 & Malinkundang & datuk maringgit & 1 & Edit & Hapus \\
\hline 2 & Pulang & Tereliye & 2 & Edit & Hapus \\
\hline
\end{tabular}

d. Tampilan Data Kelas

\section{Perpustakan}

\section{SMPN 3 HURAGI}

Sistem Perpustakaan Online

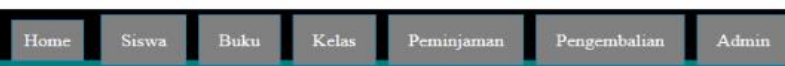

Data Kelas

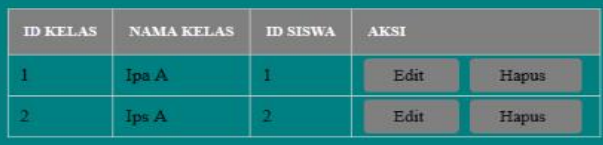

e. Tampilan Data Peminjaman

\section{Perpustakan}

\section{SMPN 3 HURAGI}

Sistem Perpustakaan Online

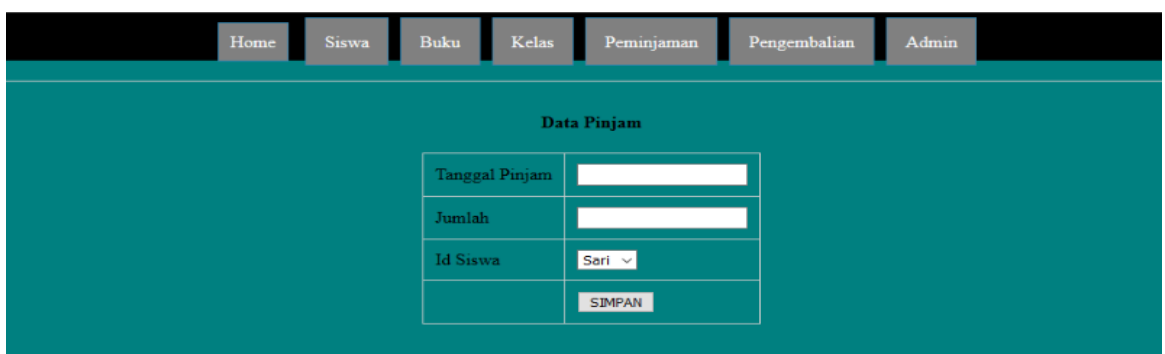

f. Tampilan Data Pengembalian

\section{Perpustakan}

SMPN 3 HURAGI

Sistem Perpustakaan Online

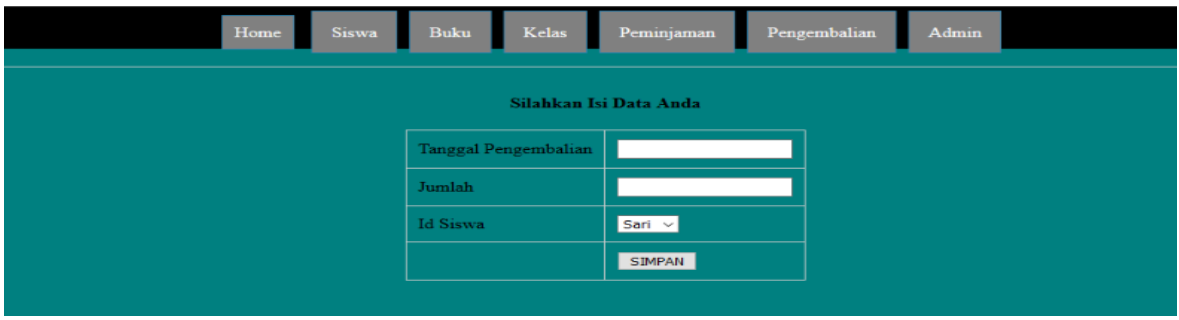

g. Tampilan Data Admin 


\section{Perpustakan}

Sistem Perpustakaan Online

\section{SMPN 3 HURAGI}

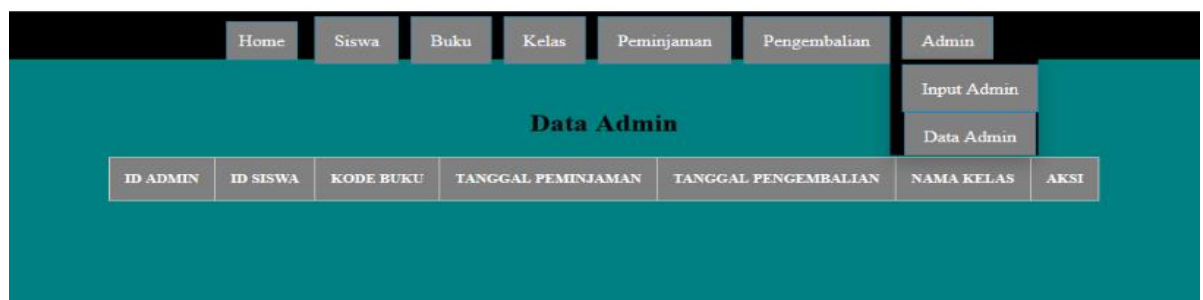

\section{Pengujian}

Tahap testing dilakukan setelah proses pemrograman sistem selesai dilakukan. Pengujian sistem dilakukan dengan membandingkan antara sistem informasi perpustakaan yang masih manual dengan sistem informasi yang sudah komputerisasi.

\section{Kesimpulan}

Berdasarkan pengujian dan pembahasan maka dapat di tarik kesimpulan sebagai berikut :

Kesimpulan

1. Sistem dirancang untuk mendapatkan informasi tantang data buku perpustakaan.

2. Sistem dirancang agar mengetahui siswa dan siswi yang sering berkunjung ke perpustakaan.

3.

perpustakaan ini juga memudahkan user/administrator tentang memanajemen buku.

\section{Referensi}

- Kadir, Abdul. 2013. Pengenalan SISTEM INFORMASI edisi Revisi. Yogyakarta: Andi

- Witarto. (2004). Mengenali Sistem Informasi. Bandung: Informatika. 